\title{
Projetos Tuning e Tuning América Latina: Afinando os Currículos às Competências
}

\author{
Maria |dati Eiró() \\ Afrânio Mendes Catani(*)
}

Resumo: A convergência do ensino superior na União Europeia, por meio do acordo de Bolonha, é uma realidade. Neste acordo, está prevista uma reforma curricular universitária que se propõe a alinhar a formação ao mercado laboral. A forma como os países encontraram para redefinir seus currículos foi a união em torno do projeto Tuning. O objetivo do presente artigo é apresentar e discutir o projeto Tuning e seu correspondente latino-americano, sendo a principal conclusão que os Projetos Tuning; tanto na União Europeia quanto na América Latina, servem aos propósitos dos setores produtivos, encontrando respaldo nas estruturas capitalistas dos blocos econômicos em que estão inseridos.

Palavras-chave: Projeto Tuning, Projeto Tuning América Latina, Acordo de Bolonha, Ensino Superior

Abstract:

The convergence of higher education through the Bologna process, is a reality. The Bologna agreement states an academic curriculum oriented towards the market. Their curricula is redefined around the Tuning project. The aim of this article is to present and discuss the Tuning project and its corresponding in Latin America. The main conclusion is that they serve to the purposes of the productive sectors, finding support in the capitalist structures of the economic blocs in which they exists.

Key-words: Tuning Project, Tuning Latin America Project, Bologna agreement, Higher Education.

(*) Doutora em Integração da América Latina/USP — Brasil. E-mail: $<$ idati@usp.br >.

(**) Professor Titular na Faculdade de Educação da Universidade de São Paulo. Professor no Programa de Pós-Graduação em Integração da América Latina (PROLAM)-USP — Brasil. E-mail:<amcatani@usp.br>. Recebido em 4.3.2011 e aceito em 20.6.2011. 


\section{INTRODUÇÃO}

O Tratado de Bolonha, caracterizado como um acordo firmado por diversos países europeus em 1999 na cidade de Bolonha, Itália, para convergência dos sistemas de ensino superior do continente, tem como mola propulsora o aumento da competitividade econômica europeia no cenário mundial.

Neste contexto, os processos de produção aliam-se à formação profissional, sendo que a convergência tem seu foco, entre outras, na formação de mão de obra qualificada para as diversas frentes de trabalho existentes. Com o objetivo de elevar a competitividade educacional internacional, o conhecimento privilegiado é o conhecimento instrumental.

A formação universitária estrutura-se voltada para a busca dos resultados por meio da competitividade, em resposta aos anseios da lógica empresarial, do mercado e de seus clientes. Como explicam Catani e Oliveira (2002):

A lógica e as ações que presidem a desorganização da educação superior ocorrem na direção de tornar o trabalho acadêmico mais produtivo do ponto de vista dos interesses prevalecentes no mercado. Esta racionalidade econômica revela que a universidade e o trabalho acadêmico só possuem relevância econômica e social quando formam profissionais aptos às necessidades atuais do mercado de trabalho e quando pesquisam, geram ou potencializam os conhecimentos, as técnicas e os instrumentos de produção e serviços que possibilitam a ampliação do capital. (CATANI; OLIVEIRA, 2002, p. 24.)

LIMA (1997) complementa essa ideia ao declarar que:

Este modelo gerencial representa por referência básica o atendimento à lógica empresarial e ao mercado competitivo, adotando concepções instrumentais/funcionais de autonomia e de participação. O setor privado, através de dispositivos variados, constitui-se numa fonte de inspiração privilegiada e, nas suas versões mais puras, a fórmula apregoada para sua superação da crise de legitimidade aparece associando-a a uma imagem de moderna estação de serviços, funcionalmente adaptada às exigências do mercado dos seus clientes e consumidores. (LIMA, 1997, p. 38.)

Paralelamente à implantação de Bolonha e inseridas neste contexto, algumas universidades do bloco europeu fixaram pontos comuns de referência para currículos baseados em competências, com a finalidade de padronização e entendimentos comuns. Essas universidades devem trabalhar em conjunto os aspectos que gostariam de ver unificados, sobretudo, no que se refere ao aspecto pedagógico dos cursos universitários. Assim, nasceu o Projeto Tuning.

Universidades latino-americanas, por sua vez, apresentaram ao bloco europeu o projeto Tuning América Latina, procurando alinhar as propostas e ideais de trabalho com a União Europeia.

\section{A FormaÇÃo POR COMPETÊNCIA COMO ESTRATÉGIA DIDÁtiCA PARA O SETOR PRODUTIVO}

Tuning, característico do novo modelo educacional de Bolonha, propõe-se a elaborar currículos baseados em competências e a determinar pontos de referência para as competências genéricas e específicas de cada disciplina de cada curso universitário. 
Philippe Perrenoud define competência como a faculdade do indivíduo de mobilizar um conjunto de recursos (saberes, capacidades cognitivas, capacidades físicas, informações etc.) para solucionar de forma eficaz uma determinada situação (PERRENOUD, 2000). Para ele, competência compreende atributos de diferentes naturezas:

1. Atributo de conhecimento (saber saber) — trata-se do âmbito cognitivo do desempenho, ou seja, o saber prático e teórico;

2. Atributo de habilidade (saber fazer) — trata-se do âmbito operativo do desempenho, ou seja, saber fazer com eficiência;

3. Atributo de atitude (saber ser, querer fazer) — trata-se do âmbito afetivo e moral do desempenho, inclui traços de personalidade, caráter, valores e crenças, projetando profissionalmente, como envolvimento, comprometimento, ética, responsabilidade, disponibilidade e flexibilidade para a abertura a novas visões, empatia, cooperação e solidariedade.

Perrenoud (2000) caracteriza competência como a capacidade de transferir o que foi aprendido, de ter autonomia na aprendizagem e na resolução de problemas. Para o autor, o enfoque por competência é uma maneira de retomar uma problemática antiga, a de "transferência de conhecimentos", e de empregá-la em uma prática requerida.

A mobilização exerce-se em situações complexas, que obrigam a estabelecer o problema antes de resolvê-lo, a determinar os conhecimentos pertinentes, a reorganizá-los em função da situação, a extrapolar ou preencher as lacunas. Entre conhecer a noção de juros e compreender a evolução da taxa hipotecária, há uma grande diferença. Os exercícios escolares clássicos permitem a consolidação da noção e dos algoritmos de cálculo. Eles não trabalham a transferência. Para ir nesse sentido, seria necessário colocar-se em situações complexas como obrigações, hipotecas, empréstimo, leasing. Não adianta colocar essas palavras nos dados de um problema de matemática para que essas noções sejam compreendidas, ainda menos para que a mobilização dos conhecimentos seja exercida. Entre saber o que é um vírus e proteger-se conscientemente das doenças virais, a diferença não é menor. Do mesmo modo que entre conhecer as leis da física e construir uma barca, fazer um modelo reduzido voar, isolar uma casa ou instalar corretamente um interruptor. (PERRENOUD, 1999, p. 16.)

Marchesi (2007) define competência como a capacidade de desenvolver-se em um determinado âmbito e de utilização dos conhecimentos necessários, com eficácia, nas atividades e tarefas a ele relacionadas. Ter competência para exercer uma ação ou executar uma tarefa é ter êxito na sua execução, de forma demonstrada e efetivada. Desta forma, a competência necessária deve ser demonstrada em ações.

Trabalhar com o conceito de competência necessariamente envolve a transferência e a mobilização de capacidades e conhecimentos em situações reais (Le Boterf, 2003). Para Rué (2009), "competência é a forma como uma pessoa expressa o conjunto do próprio conhecimento em uma situação concreta” (RUÉ, 2009, p. 25).

No projeto denominado Definição e Seleção de Competências (DeSeCo - Definition and Selection of Competencies), da Organização para a Cooperação e Desenvolvimento 
Econômico - OCDE (Organisation for Economic Co-Operation and Development - OECD, 2002), encarregado de definir e selecionar as competências consideradas essenciais para a vida das pessoas e ao bom funcionamento da sociedade, o termo competência é definido como a capacidade de responder às demandas complexas e levar a cabo tarefas diversas de forma adequada. Supõe uma combinação de habilidades práticas, conhecimentos, motivação, valores éticos, atitudes e outros componentes sociais e de comportamento que, conjuntamente, devem lograr uma ação eficaz. Disponível em: <http://www.deseco.admin.ch/bfs/deseco/ en/index/02.html $>$. A OCDE prevê uma definição de competência derivada da experiência cotidiana de cada indivíduo e ambiente de trabalho.

Muito embora Rué (2009) demonstre que o conceito está cercado de mal-entendidos e ainda encontra-se em construção, para muitos autores, competência relaciona-se tão somente ao sucesso profissional. $\mathrm{O}$ autor caracteriza o termo habilidade, "entendido instrumentalmente com relação ao posto de trabalho" (RUÉ, 2009, p. 29), proveniente de uma relação do homem com a máquina, e sua ampliação no novo contexto social da competência. Segundo Rué (2009), a associação do termo — e a consequente reserva a ele — aconteceu porque o conceito de competência no contexto educacional foi mediado por assessores de organismos internacionais (como a OCDE), e por autoridades políticas e administrativas, o que "o tornou suspeito" (RUÉ, 2009, p. 17).

Para Frigotto (2007), o desenvolvimento dos conceitos de competência e empregabilidade significa que "não há lugar para todos e o direito social e coletivo reduzem-se ao direito individual" (FRIGOTTO, 2007, p. 1.138). A valorização do conhecimento se dá também como parâmetro de ascendência ao poder.

Ramos (2002), por sua vez, discute que as transformações atuais no capitalismo produzem um deslocamento conceitual de qualificação para o de competência, sendo que esta última ganha gradativamente relevância frente à noção de qualificação. Enquanto a noção de qualificação surge no modelo fordista de produção, a noção de competência advém da sua crise, isto é, da renovação do modelo capitalista produtivo. Isto significa que a noção de competência pode ser vista como uma atualização do conceito de qualificação.

Ferretti (1999) também acredita na atualização dos termos, colocando o conceito como uma forma de o capital se reorganizar para obter uma valorização mais rápida. Frigotto (1989) escreve que a qualificação, diferentemente das competências, pressupõe uma ausência de regulações sociais. Aplicadas ao mundo do trabalho, as regulações sociais visam reconhecer o trabalhador como membro de um coletivo e não apenas um indivíduo com um contrato de trabalho (CASTEL, 1998).

Para Amaro (2008), a noção de competência em empresas, nas atividades gerenciais, tende a individualizar as relações e enfraquecer a dimensão de qualificação. As qualificações dos trabalhadores são questionadas e o mercado passa a exigir profissionais com maior iniciativa e que assumam mais responsabilidades. O termo competência aparece, portanto, para expressar as novas características requeridas do trabalhador: iniciativa, flexibilidade, cooperação, autonomia.

Quanto ao âmbito profissional, as competências podem se estabelecer em três níveis: competências básicas, genéricas e específicas. A competência básica mostra a capacidade 
de colocar em prática de forma integrada, conhecimentos, habilidades, atitudes para encontrar situações e resolver problemas. Básica, porque deve estar ao alcance de todos os sujeitos implicados, ou seja, ao alcance de todos os alunos, independente das condições sociais, sexo ou qualquer outra característica, muito embora Rué (2009), por exemplo, entenda o termo básico como muito restritivo, com alusão à alfabetização, preferindo o termo competência-chave para as que aqui denominamos competências básicas. De toda forma, trata-se de capacidade mais do que de conteúdo e deve permitir que os indivíduos atuem de maneira responsável na realidade da vida cotidiana.

Nesta abordagem, para se definir uma competência como básica, é necessário que:

- contribua com a obtenção de resultados de alto valor pessoal e social;

- seja aplicável a uma ampla gama de contextos relevantes;

- seja benéfica para toda a população.

As competências genéricas são uma combinação de atributos que se referem a uma formação completa do conhecimento - o desenvolvimento de habilidades práticas e habilidades instrumentais e cognitivas para competir no mundo globalizado (DELORS, 1996).

As competências específicas dizem respeito a uma dada situação, usualmente vinculadas a uma prática profissional especializada, e se referem a habilidades próprias de cada perfil profissional e de suas especializações.

As competências profissionais são fruto de uma base estável. Esta base, se bem formada, possibilita que a competência profissional ou específica se desenvolva com mais facilidade. Todavia, se não existe uma base, ou se ela está pouco desenvolvida, será quase impossível chegar-se a uma meta, mesmo com o grande envolvimento de todos os participantes. Pode acontecer, por exemplo, de o aluno obter as notas necessárias para a sua aprovação nos exames e que seja oficialmente considerado qualificado para uma função. Se não tiver as bases necessárias, ele não será o funcionário competente que a empresa deseja, pelas competências básicas que lhe faltam. O que importa é "que as competências profissionais estejam completas e possam ser verificadas" (FRAILE e VERA, 2008, p. 10).

O exercício da competência passa por operações mentais complexas (esquemas de pensamento), que permitem determinar e realizar uma ação; as competências profissionais constroem-se em situações de trabalho - portanto, em situações práticas. Pode-se, por exemplo, conhecer técnicas ou regras de gestão contábil e não saber aplicá-las no momento oportuno, especialmente se as competências básicas não forem suficientemente sólidas. Ou seja, as competências são elas mesmas saberes ou atitudes e devem ser demonstradas por meio de situações práticas.

O sucesso de uma organização depende do desempenho humano, razão pela qual se desenvolve e se organiza numa forma de atuação sobre o comportamento, que se convencionou chamar de modelo de gestão de pessoas. Assim, gestão de pessoas é a maneira pela qual a empresa se organiza para gerenciar e orientar o comportamento humano no trabalho, definindo princípios, estratégias, políticas e práticas ou processos de gestão. Por meio desses mecanismos, implementa diretrizes e orienta os estilos de atuação dos gestores em sua relação com aqueles que nela trabalham (Dutra, 2001). 
Picarelli Filho (1997) atribui vários fatores ao crescente interesse pelo tema "competência":

a) O crescimento do setor de serviços na economia e a consequente forte demanda por profissionais mais qualificados.

b) A ascensão das empresas de alta tecnologia e de serviços especializados.

c) A reestruturação de empresas, com a reorganização de estruturas hierárquicas rígidas e a implementação de sistemas mais flexíveis.

A ação profissional supõe que o indivíduo deva esmerar-se na construção das suas competências, identificando e construindo seus recursos cognitivos, treinando sua mobilização em situações de exigências profissionais e sendo possuidor de uma postura reflexiva e profissionalizante que o impulsiona a tornar-se condutor de sua formação

Para Rué (2009), as competências são de natureza complexa e englobam habilidades, conhecimentos e atitudes dos indivíduos, sem serem reduzidas a uma ou outra dessas características. É importante ressaltar também que competências não devem ser confundidas com aptidão ou inteligência, uma vez que podem ser desenvolvidas e construídas nos indivíduos.

Fleury e Fleury (2000) e Dutra (2001) desenvolveram uma proposta conceitual com a abordagem mais comportamental para a noção de competência nas organizações, em que os resultados estão atrelados ao desenvolvimento profissional e pessoal dos indivíduos. Para Dutra (2001), a competência está vinculada à capacidade de entrega do indivíduo, realizada a partir da aplicação do estoque de repertórios individuais e organizacionais.

O êxito das ações profissionais pode ser verificado por meio de:

- competências instrumentais: caracterizam-se como uma habilidade de comunicação, envolvendo a capacidade de expressar ideias de forma lógica e com clareza verbal. Supõem o uso de uma linguagem precisa, específica e concreta;

- competências transversais: é o desenvolvimento de processos que contribuam para que os indivíduos sejam progressivamente mais ativos, autônomos e colaborativos, considerando o meio social em que vivem. A transversalidade prevê que os conhecimentos sejam oriundos de várias esferas do saber, caracterizando-se inclusive, por atitudes de constante busca pelo aprimoramento e desenvolvimento intelectual ${ }^{(1)}$.

Essas competências podem ser desenvolvidas e aprimoradas. Isto significa que devem fazer parte dos currículos escolares, desde o ensino básico, culminando com as tarefas propostas às esferas profissionalizantes, em programas de ensino técnico.

Idealiza-se individualmente o desenvolvimento da carreira profissional para se atingir os objetivos organizacionais. Dessa forma, em uma esfera profissional, o desejo mercadológico fica incorporado ao desejo do indivíduo. Não se trata, portanto, de fazer sem consciência, mas sim, de fazer de forma a se auferir lucros, de se manter um nível de empregabilidade

(1) Disponível em: <http://www.uva.es/> Acesso em: 21 set. 2009, em: 13 ago. 2009 
e de se aprender conforme os interesses mercadológicos atuais. A ideia de competência ganha força, portanto, na capacidade de transformar tecnologia em produto com capacidade de consumo (Machado, 2009). E é aprimorada por meio de sua inserção nas estruturas curriculares dos cursos que formam para o mercado de trabalho. Esta inserção acontece por meio dos Projetos Tuning:

\section{Projeto Tuning}

O Projeto Tuning teve início no ano de 2000 com o objetivo de formatar as estruturas educacionais superiores europeias propostas por Bolonha. Trata-se de um projeto que deve ser realizado e idealizado no interior das universidades e nelas testados, para posterior ampliação do conceito da convergência do ensino. Tuning, em termos musicais, significa afinar, ou seja, busca-se alinhar os ideários de Bolonha às propostas educacionais existentes nas universidades.

Em 2003, em Berlim, reiterou-se a necessidade de implementar ações com vistas a se "afinar" o Espaço Europeu do Ensino Superior ao Espaço Europeu de Investigação. Os ministros ali reunidos firmaram o compromisso de estabelecer até 2005 medidas relativas ao desenvolvimento de um Marco Europeu de Qualificações (EFQ), cuja linguagem é base para o Projeto Tuning.

O desenvolvimento do EFQ se baseia, essencialmente, em resultados do trabalho da Iniciativa Conjunta de Qualidade (JQI) e do Projeto Tuning (González; Wagenaar e Beneitone, 2004).

No âmbito universitário, Tuning permite o avanço da reforma curricular, acompanhado da possibilidade de se instaurar estruturas formativas baseadas em competências (Pena-Vega, 2009). A ideia principal está na reestruturação e revitalização dos currículos, principalmente no que se refere à qualidade das formações, tornando o aluno parte integrante e ativa do aprendizado.

Os países e universidades que integram os Projetos Tuning Europeu e Tuning América Latina podem ser conhecidos nos Anexos 1 e 2.

Tuning é um projeto iniciado por instituições de ensino superior da Europa e expandido para outras regiões, inclusive para a América Latina, que desenvolve pontos comuns de referência para currículos baseados em competências, subdivididos em diferentes áreas.

As competências descrevem os resultados da aprendizagem, aplicando-se tanto às competências específicas como às competências genéricas. Os resultados da aprendizagem especificam os requerimentos mínimos para se obter os créditos de Bolonha. Desta forma, a Pedagogia por Competências, nos Projetos Tuning, passa a ser uma referência para a elaboração e avaliação dos planos de estudo. Ela permite flexibilidade e autonomia na elaboração desses planos, mas, ao mesmo tempo, introduz parâmetros comuns de equivalência e de objetivos de cada plano (detalhes em: <http://www.dges.mctes.pt/DGES/pt/Estudantes/Processo+ $\mathrm{de}+$ Bolonha/Objectivos/Descritores+Dublin/ $>$ ). 
Para Pallisera, Fullana, Planas e Valle (2010), este é um momento europeu de grandes possibilidades, inclusive pela maior flexibilidade na formulação das competências profissionais, na organização dos conteúdos e na reorientação das metodologias educativas sem o condicionamento a uma estrutura disciplinar rígida.

Vejamos um dos princípios constantes do Diario Oficial de la Unión Europea relativa a "la creación del Marco Europeo de Cualificaciones para el aprendizaje permanente":

El desarrollo y el reconocimiento de los conocimientos, las destrezas y la competencia de los ciudadanos son esenciales para el desarrollo individual, la competitividad, el empleo, y la cohesión social de la Comunidad. Este desarrollo y reconocimiento deben facilitar la movilidad transnacional de los trabajadores y las personas en proceso de aprendizaje y contribuir a cubrir las necesidades de oferta y demanda en el mercado europeo de trabajo. Por consiguiente, conviene promover y mejorar el acceso de todos, incluidas las personas desfavorecidas, al aprendizaje permanente y la participación en el mismo, así como el reconocimiento y el uso de las cualificaciones a nivel nacional y comunitario. (Diario Oficial de la Unión Europea, 23 abr. 2008.)

O Projeto Tuning é delineado em quatro grandes linhas:

- Linha 1: definição das competências acadêmicas genéricas para todas a graduações;

- Linha 2: definição das competências específicas para cada graduação (conhecimentos e destrezas);

- Linha 3: utilização do sistema europeu de créditos (ECTS) como estratégia de acumulação e transferência;

- Linha 4: definição dos métodos de ensino, aprendizagem e avaliação.

Desta forma, buscam-se pontos de convergência para o reconhecimento das titulações e a fixação de pontos de referência para uma fala e entendimentos comuns (Beneitone; Esquetini; González; Maletá; Siufi e Wagenaar, 2007). Em teoria, não se pretende restringir a autonomia do mundo acadêmico e dos especialistas de cada disciplina e, menos ainda, das autoridades acadêmicas locais e nacionais (ver: < http://ec.europa.eu/education/policies/ educ/Tuning/Tuning_es.html>), mas apenas ser referência.

Neste projeto, os diferentes tipos de competências representam uma combinação de atributos - que dizem respeito ao conhecimento e sua aplicação e às atitudes e responsabilidades - e descrevem os resultados de aprendizagem de um determinado programa de estudos. O objetivo é observar como os alunos serão capazes de se desenvolver ao término do processo educacional. Observemos a classificação das competências no Esquema Tuning. 


\section{Figura 1 - Esquema Tuning: Tipos de competências do Projeto Tuning}

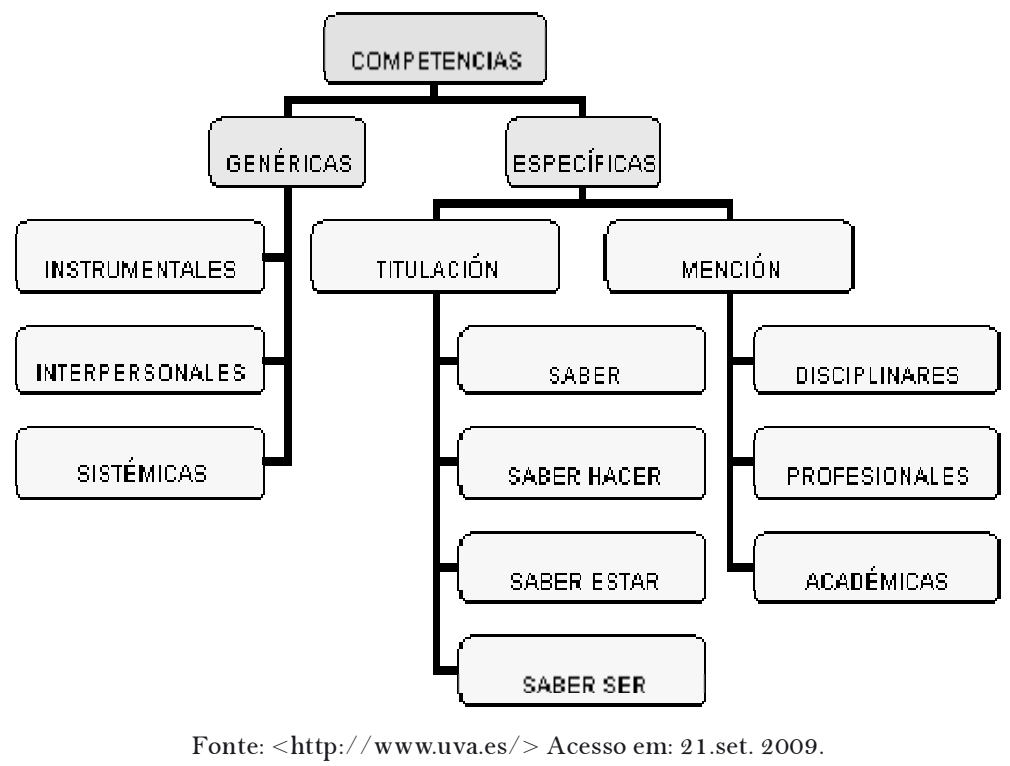

As competências genéricas são as que possuem elementos comuns a todas, ou pelo menos, à maioria das titulações e são essenciais aos indivíduos, independente da titulação escolhida. São atributos como capacidade de aprender, de tomar decisões, de elaborar projetos, destrezas administrativas. O projeto Tuning detalha de maneira mais específica as competências:

- Competências Instrumentais: habilidades de desempenho relacionadas com as capacidades cognitivas, metodológicas, tecnológicas;

- Competências Interpessoais: habilidades de desempenho relacionadas com a capacidade de um bom relacionamento social e cooperação;

- Competências Sistêmicas: habilidades de desempenho relacionadas à visão de conjunto e à capacidade de gerir um projeto na sua totalidade;

- Competências Específicas: habilidades vinculadas a uma titulação, o que requer identidade e consistência social e profissional ao perfil formativo.

A proposta é determinar pontos de referência para as competências genéricas e específicas de cada disciplina do ciclo universitário, graduação e mestrado, nas áreas: administração, educação, geologia, história, matemática, física e química. Outras áreas já estão sendo contempladas. Como as competências definidas descrevem os resultados desejados ao longo da aprendizagem, Tuning caracteriza-se, então, como uma mediação pedagógica focalizada nos resultados de aprendizagem e nos desempenhos de tarefas.

Como as competências propostas são tanto as específicas quanto as genéricas, elas são pontos de referência para a elaboração dos planos de estudos e, portanto, não podem ser rígidas. Mais de 100 instituições representativas dos países da União Europeia participaram da primeira fase do projeto (2000-2002), coordenado pelas universidades de Deusto 
(Espanha) e Groningen (Países Baixos). Nessa primeira fase, foi dada especial ênfase às definições das ações:

1. competências genéricas;

2. competências disciplinares específicas;

3. o papel dos sistemas de créditos (sistema ECTS).

Na segunda fase (2003-2004), especial atenção foi dada aos "enfoques da aprendizagem, didáticos e da avaliação e na função da promoção da qualidade no processo educacional" (< http://www.unideusto.org/tuningeu/images/stories/Publications/Tuning_A_Latina_ Portu_1.pdf>, p. 329).

Na primeira fase, o Tuning europeu realizou um estudo envolvendo professores, profissionais e empregadores de cada uma das áreas de conhecimento. Foram 135 Universidades participantes. Os resultados deste estudo mostram, para os professores de todas as áreas, que a competência mais importante é a capacidade de análise e síntese ou a capacidade de aprender e a capacidade de resolver problemas. Entre os profissionais e empregadores, cujas opiniões se colocaram mais próximas entre si e mais distantes do que pensam os professores, dentre as competências genéricas, ambos destacaram a capacidade de aplicar os conhecimentos adquiridos (González; Wagenaar e Beneitone, 2004). Isto demonstra uma expectativa por parte dos empregadores em obterem egressos com conhecimentos práticos para aplicação específica em suas carreiras profissionais.

\section{Tuning América Latina: A AProximaÇão latino-AMEricana À política edUCACiOnal EUROPEIA}

Para determinar las implicancias del Proceso de Bolonia en la definición de las políticas públicas resulta vital considerar el Proyecto Tuning implementado en las universidades chilenas desde el año 2005. (ARGÜELLES, 2009, p. 252.)

Representantes da América Latina elaboraram um projeto similar ao Tuning Europa e o apresentaram à Comissão Europeia no final do mês de Outubro de 2003, com os mesmos pontos de referência, compreensão e confluência (González; Wagenaar e Beneitone, 2004) no ensino superior, de forma transnacional e transregional.

Tuning América Latina é financiado pela União Europeia com a proposta de realizar estudos comparativos das habilidades dos currículos de diversas áreas (Nobre, 2009).

O projeto que começou com 62 universidades, conta hoje com 190 instituições de 19 países da América Latina (NOBRE, 2009). As universidades participantes foram selecionadas pelos Ministérios de Educação, Conselhos de Educação Superior e/ou Conferências de Reitores de cada um dos países latino-americanos.

Em março de 2005, houve a realização de duas Reuniões na Argentina (Buenos Aires) e outra em agosto, no Brasil (Belo Horizonte). Em fevereiro de 2006, com um maior número de universidades participantes e a inclusão de novas áreas de conhecimento, ocorreu a primeira Reunião Geral do Tuning América Latina, na cidade de San José, Costa Rica. 
Com isso, teve início uma nova fase do Projeto, cujos esforços se dirigiram ao estudo das Competências Específicas (González e Wagenaar, 2006).

A necessidade de se confrontar com diferentes crenças e culturas é um percurso imprescindível para assegurar uma formação completa e competitiva em nível educacional internacional. Dentre os princípios básicos observados no projeto Tuning América Latina, é essencial a preservação das identidades culturais regionais, a proteção das diversidades de cada país e a autonomia das universidades.

A proposta Tuning para América Latina é uma ideia intercontinental, com os seguintes objetivos, conforme assinalado em seu sítio: <http://Tuning.unideusto.org/Tuningal/ index.php?option $=$ content $\&$ task $=$ view $\&$ id $=171 \&$ Itemid $=199>$. Negritos nossos.

- Contribuir para o desenvolvimento de titulações facilmente comparáveis e compreensíveis de forma articulada em toda América Latina;

- Impulsionar, em escala latino-americana, um importante nível de convergência da educação superior em quatro áreas temáticas (Administração de Empresas, Ciências da Educação, História e Matemáticas) por meio das definições aceitas em comum, produto de resultados profissionais e de aprendizado;

- Desenvolver perfis profissionais em termos de competências genéricas e relativas a cada área de estudos incluindo destrezas, conhecimentos e conteúdo nas quatro áreas temáticas que são incluídas no projeto;

- Facilitar a transparência nas estruturas educativas e impulsionar a inovação através da comunicação de experiências e da identificação de boas práticas;

- Criar redes capazes de apresentar exemplos de práticas eficazes, estimular a inovação e a qualidade por meio da reflexão e do intercâmbio recíproco;

- Desenvolver e intercambiar informação relativa ao desenvolvimento dos currículos nas áreas selecionadas e criar uma estrutura curricular modelo expressa por pontos de referência para cada área, promovendo o reconhecimento e a integração latino-americana de titulações;

- Criar pontes entre as universidades e outras entidades apropriadas e qualificadas para produzir convergência nas áreas das disciplinas selecionadas.

Tuning América Latina tem quatro grandes linhas:

1. Competências (genéricas e específicas): a Pedagogia por Competências;

2. Formas de ensino, aprendizagem e avaliação: métodos de ensino e envolvimento em diferentes contextos de aprendizagem, tendo o aluno - e seu interesse pelo estudo - como protagonista principal deste processo;

3. Créditos acadêmicos: é a medida de aprendizagem e de equiparação das disciplinas entre os diversos países. Aqui é essencial a boa relação entre as várias universidades, como garantia de mobilidade estudantil e profissional, baseados na correspondência dos conteúdos disciplinares;

4. Qualidade dos programas. 
Na página oficial do projeto Tuning América Latina <http:/ / Tuning.unideusto.org/ Tuningal/>, são apontadas as competências genéricas e as específicas para cada curso.

Conforme o Tuning América Latina, as Competências Genéricas da América Latina foram assim definidas (disponíveis em: <http://Tuning.unideusto.org/Tuningal/index.php? option $=$ content\&task=view\&id=217\&Itemid=246>): (a) Capacidade de abstração, análise e síntese; (b) Capacidade de aplicar os conhecimentos na prática; (c) Capacidade para organizar e administrar o tempo; (d) Conhecimentos sobre a área de estudo e sobre a profissão; (e) Responsabilidade social e compromisso com a cidadania; (f) Capacidade de comunicação oral e escrita; (g) Capacidade de comunicação em um segundo idioma; (h) Habilidades no uso das tecnologias da informação e comunicação; (i) Capacidade de investigação; (j) Capacidade de aprender e atualizar-se permanentemente; (k) Habilidades para buscar, processar e analisar informações procedentes de fontes diversas; (l) Capacidade crítica e autocrítica; (m) Capacidade para atuar em novas situações; (n) Capacidade criativa; (o) Capacidade para identificar e resolver problemas; (p) Capacidade para tomar decisões; (q) Capacidade de trabalho em equipe; (r) Habilidades interpessoais; (s) Capacidade de motivar e conduzir em direção a metas comuns; (t) Compromisso com a preservação do meio ambiente; (u) Compromisso com seu meio sociocultural; (v) Valoração e respeito pela diversidade e multiculturalidade; (w) Habilidade para trabalhar em contextos internacionais; (x) Habilidade para trabalhar de forma autônoma; (y) Capacidade para formular e gerir projetos; (z) Compromisso ético; (aa) Compromisso com a qualidade.

No sítio do Tuning América Latina, é possível observar as competências genéricas e as específicas fixadas para cada profissão.

Krawczyk (2008) acredita que há uma tentativa de integração universitária latino-americana e que ela segue os moldes da União Europeia, isto é, "de cima para baixo" (KRAWCZYK, 2008, p. 44). Pena-Vega (2009) explicita que, ao menos no México, onde o processo foi implementado de maneira hierárquica e sem discussão entre os principais envolvidos, os avanços acontecem de maneira lenta; ao contrário, nas universidades que promoveram debates e grupos de discussão, os processos encontram-se avançados e com o apoio da maioria dos setores.

No México, os esforços para se incorporar ao Processo de Bolonha se transformaram em um mecanismo duplo: de um lado a elitização das instituições educativas (as instituições de excelência, globalizadas) e, de outro, a massificação sem qualidade da maioria das Instituições de Ensino Superior, que devem ficar à margem do processo de globalização (PENA-VEGA, 2009). Isto se deve ao fato de muitas universidades oferecerem cursos rápidos, com o objetivo único de colocação do egresso no mercado de trabalho. Alguns alunos, os pertencentes à elite educacional, por outro lado, demonstram existir uma demanda por cursos de formação mais completa ou integral.

$\mathrm{Na}$ Venezuela, por influência do projeto Tuning, algumas universidades iniciaram suas estruturas curriculares com perfis acadêmico-profissionais baseados em competências (PENA-VEGA, 2009).

O Chile é o país na América Latina que mais incorporou em suas discussões a possibilidade de convergência educacional nos moldes de Bolonha. Existem propostas nacionais 
de flexibilização curricular para transferências de créditos, de validação de títulos acadêmicos e uma expressiva atuação no projeto Tuning América Latina (Argüelles, 2009). Pey (2007), por meio do sítio oficial do Ministério de Educação do Chile — área Ensino Superior (MECESUP) - apresenta no Quadro 1 a situação do Tuning Chile comparado ao Tuning Europeu.

\section{Quadro 1 - Comparação do Tuning Europeu com o Tuning Chileno, segundo PEY}

\begin{tabular}{|c|c|}
\hline $\begin{array}{c}\text { Tuning } \\
\text { PROCESSO EUROPEU }\end{array}$ & $\begin{array}{c}\text { Tuning } \\
\text { PROCESSO CHILENO }\end{array}$ \\
\hline Declaração de Bolonha em 1999 & Início das reformas curriculares em 1999 \\
\hline $\begin{array}{c}\text { Processo top-down (de cima para baixo, } \\
\text { sem discussões prévias entre os envolvidos) }\end{array}$ & $\begin{array}{l}\text { Processo bottom-up (processo iniciado a partir das } \\
\text { discussões com os envolvidos, a partir das bases) }\end{array}$ \\
\hline $\begin{array}{c}\text { ECTS (sistema de créditos) em implementação } \\
\text { avançada }\end{array}$ & $\begin{array}{l}\text { SCT-CHILE (sistema de créditos chileno) } \\
\text { em implementação inicial }\end{array}$ \\
\hline Mobilidade massiva & $\begin{array}{l}\text { Mobilidade incipiente. Processo que } \\
\text { interessa como modelo regional }\end{array}$ \\
\hline $\begin{array}{l}\text { Reuniões de Ministros de Educação } \\
\text { e Comissão Europeia }\end{array}$ & Conselho de Vice-reitores Acadêmicos \\
\hline Convergência do processo & Divergência quanto aos objetivos do processo \\
\hline
\end{tabular}

Fonte: <www.uctemuco.cl/docencia/seminario/presentaciones/rpey.pdf $>$ Acesso em: 23. nov. 2009.

O Tuning latino-americano aqui é denominado chileno, porque o Chile, posicionando-se ativamente perante as transformações educacionais propostas, conduziu o processo na reunião no México em 2007 (Pey, 2007).

No Chile, no que se refere ao processo com envolvimento das bases na sua formulação, os informes demonstram uma ativa participação de alunos, empregadores, docentes e funcionários nas definições das competências específicas desejadas por área de conhecimento (Pey, 2007).

O México apoia politicamente os acordos de Bolonha e participa no projeto Tuning América Latina sob a responsabilidade da Subsecretaria de Educação Superior da Secretaria de Educação Pública. Consciente das dificuldades de se formar um espaço comum de educação superior em bloco, o país cria um Consórcio de Universidades Mexicanas (CUMex) com o objetivo de sedimentar um espaço comum mexicano de educação superior, que se orienta desde o início com o objetivo de estabelecer fortes vínculos com o exterior (Pena-Vega, 2009).

Há uma expressa tentativa de envolvimento das bases e de tornar o Tuning América Latina um instrumento a favor da equivalência de diplomação e da facilitação da mobilidade estudantil e profissional.

É fundamental ressaltar que não existe um sistema de créditos na América Latina, muito embora a UNESCO tenha propostas curriculares para o continente, o que certamente se caracteriza como um fator de dificuldade para a validação de disciplinas entre as Instituições 
de Ensino Superior (IES) e de títulos entre os países do bloco. Aliado a isso, há uma imensa variedade de nomenclatura das disciplinas ${ }^{(2)}$ e uma não correspondência de ementas. Este é apenas um exemplo da dificuldade que a América Latina terá quando iniciar suas referências para a equivalência de títulos.

\section{Conclusões}

O presente trabalho se volta para a laboralidade, pela sua característica como política de formação superior dos blocos econômicos. Os projetos Tuning surgem como proposta de colocar em prática a política educacional de Bolonha e seu ideário de formação por competências.

Indivíduos competentes são aqueles que logram êxito nas suas ações. Trabalhar com competências significa que elas, se bem desenvolvidas, permitirão aos indivíduos atingir determinada realização ou desempenho. No âmbito profissional, o bom desenvolvimento de uma base de formação possibilita que a competência profissional ou específica se desenvolva facilmente, com sucesso em suas ações e com uma adequada combinação de habilidades práticas, conhecimentos, motivação, atitudes e valores éticos.

Tuning AL foi concebido como um trabalho desenvolvido por IES latino-americanas que busca construir linguagens e mecanismos comuns aos sistemas de ensino superior. Ideologicamente, é um espaço de reflexão de pessoas comprometidas com a educação superior. Ele é coordenado pela Universidade de Deusto, na Espanha, e um dos objetivos é analisar as competências que se relacionam com cada área de formação profissional, o que demonstra a tentativa de aproximação do sistema educacional europeu com o latino-americano.

Tuning caracteriza-se como uma mediação pedagógica focalizada nos resultados de aprendizagem e nos desempenhos de tarefas. É uma proposta de ação educacional voltada para o bom desempenho, essencialmente dirigida ao setor produtivo.

Da forma como hoje está colocado, os projetos Tuning caracterizam-se como uma proposta de formar prioritariamente para o mercado de trabalho - mais do que para a unificação do bloco latino-americano. Como não existe um sistema de créditos na América Latina, há uma dificuldade para a validação de disciplinas entre as IES e de títulos entre os países do bloco.

\section{REFERÊNCIAS BIBLIOGRÁFICAS}

AMARO, Rubens de Araújo. Da qualificação à competência: deslocamento conceitual e individualização do trabalhador. Revista de Administração Mackenzie, São Paulo, v. 9, n. 7, p. 89-111, nov./dez. 2008.

ARGÜELLES, Patricia. El proceso de Bolonia en América Latina: caso Chile. Institut de recherche et débat sur la gouvernance, 2009. In: <http://www.institut-gouvernance.org/fr/analyse/ficheanalyse-435.html> Acesso em: 3 fev. 2010.

(2) Conforme apontado pela Fundação Getúlio Vargas, no último Censo do MEC, em pesquisa referente a 71 cursos de pedagogia e 3.513 disciplinas no Brasil. 
BEnEITONE, Pablo; ESQUeTini, Cesar; GONZÁleZ, Julia; MAlETÁ, Maida; SiUfi, Gabriela; WAGENAAR, Robert. Reflexões e perspectivas do ensino superior na América Latina. Relatório Final — Proyecto Tuning América Latina 2004-2007. Bilbao: Universidad de Deusto, 2007.

CASTEL, Robert. As metamorfoses da questão social: uma crônica do salário. Petrópolis: Vozes, 1998. CATANI, Afrânio Mendes; OLIVEIRA, João Ferreira. Educação Superior no Brasil - reestruturação e metamorfose das universidades públicas. Petrópolis: Vozes, 2002.

DELORS, Jacques. La educación encierra un tesoro. In: Informe a la UNESCO de la Comisión Internacional sobre la educación para el siglo XXI. Madrid: UNESCO/Santillana, 1996.

DUTRA, Joel Souza (Org.). Gestão por competências: um modelo avançado para o gerenciamento de pessoas. São Paulo: Gente, 2001.

FERRETTI, Celso João. Brasil: educação e formação profissional nos anos recentes: formação sindical em debate. In: São Paulo: Núcleo Temático Educação do Trabalhador/Escola. São Paulo, n. 2,1999 .

FLEURY, Afonso Carlos; FLEURY Maria Tereza Leme. Estratégias empresariais e formação de competências. São Paulo: Atlas, 2000.

FRAILE, Juan Antonio García; VERA, Carmen Sabán, Un nuevo modelo de formación para el siglo XXI: la enseñanza basada en competências. Barcelona: Editorial Davinci, 2008.

FRIGOTTO, Gaudêncio. A relação da educação profissional e tecnológica com a universalização da educação básica. Revista Educação e Sociedade. Campinas, v. 28, n.100, p. 1.129-1.152, out. 2007.

. Trabalho, conhecimento, consciência e a educação do trabalhador: impasses teóricos e práticos. In: GOMEZ, Carlos M. (Org.). Trabalho e conhecimento: dilemas na educação do trabalhador. São Paulo: Cortez, 1989. p. 13-25.

GONZÁLEZ, Julia; WAGENAAR, Robert. Tuning educational structures in Europe. Informe Final. Projeto piloto, Fase 2, Universidades Deusto e Groningen. Bilbao: Editora da Universidade de Deusto, 2006.

GONZÁlEZ, Julia; WAGENAAR, Robert; BENEITONE, Pablo. Tuning América Latina, un proyeto de las universidades. Revista Iberoamericana de Educación, n. 35, p. 151-164, may/ago. 2004.

KRAWCZYK, Nora Rut. As políticas de internacionalização das universidades no Brasil: o caso da regionalização no Mercosul. Jornal de Políticas Educacionais, n. 4, p. 41-52, jul./dez. 2008. Disponível em: <www.nupec.ufpr/JPE/n4_5.pdf> Acesso em: 25 maio 2010.

LE BOTERF, Guy. Desenvolvendo a competência dos profissionais. Porto Alegre: Artmed, 2003.

LIMA, Licínio C. O paradigma da educação contábil: perspectivas gerencialistas no ensino superior em Portugal. In: SGUISSARDI, Valdemar; SILVA JR., João dos Reis (Orgs.). Políticas públicas para a educação superior. Piracicaba: Editora UNIMEP, 1997. p. 23-62.

MACHADO, Nilson José. Educação: competência e qualidade. São Paulo: Escrituras, 2009.

MARCHESI, Álvaro. Competencias básicas en educación. Madrid: Alianza, 2007.

NOBRE, Eloneid Felipe. Reflexões e perspectivas do ensino de física na América Latina - um relato sobre o projeto alfa Tuning-Am'derica Latina. XVIII Simpósio Nacional de Ensino de Física. Vitória, 2009. In: <http://www.sbf 1.sbfisica.org.br/eventos/snef/xviii/sys/resumos/To017-1.pdf> Acesso em: 23 jul. 2010.

PALLISERA, María; FULLAN, Judit; PLANAS, Anna e VALLE, Arantza Del (2010). Los cambios/ retos que implica la enseñanza basada en competencias y orientaciones para responder a ellos. 
Revista Iberoamericana de educación, n. 52(4). In: < http://www.rieoei.org/deloslectores/325oDiaz.pdf> Acesso em: 3 mar. 2011.

PENA-VEGA, Alfredo. O processo de Bolonha no ensino superior da América Latina. Observatório Internacional de Reformas da Universidade, 2009. Disponível em: <http://www.gulbenkian.pt/ media/files/agenda/eventos_2009/Futuro\%20de\%2oBolonha/TRADUCTION PROCESSO_BOLONHA_FINAL-4.pdf> Acesso em: 2. dez. 2009.

PERRENOUD, Philippe. Construir competências é virar as costas aos saberes? Pátio - Revista pedagógica. Porto Alegre, n. 11, p. 15-19, nov. 1999.

Dez novas competências para ensinar. Por to Alegre: Artmed, 2000.

PEY, Rosana. Informativo MECESUP2, 23 mar. 2007 - 30 mar. 2007, n. 352, Chile, 2007. Disponível em: <www.uctemuco.cl/docencia/seminario/presentaciones/rpey.pdf> Acesso em: 23 nov. 2009.

PICARELLI FILHO, Vicente. Remuneração por habilidades e competências: preparando a organização para a era das empresas de conhecimento intensivo. São Paulo: Atlas, 1997.

RAMOS, Marise Nogueira. A educação profissional pela pedagogia das competências: para além da superfície dos documentos oficiais. Revista Educação e Sociedade, Campinas, SP, v. 23, n. 80, p. 405-427, 2002.

RUÉ, Joan. A formação por meio de competências: possibilidades, limites e recursos. In: ARANTES, Valéria Amorim (Org.). Educação e competências: pontos e contrapontos. São Paulo: Summus, 2009. p. 15-76.

\section{Sítios:}

Projeto Tuning - Disponível em: < http://Tuning.unideusto.org/Tuningal/> Acesso em: 23 maio 2008.

DeSeCo - Definition and Selection of Competencies - OCDE. Disponível em: <http:// www.deseco.admin.ch/bfs/deseco/en/index/02.html> Acesso em: 24 maio 2010.

Projeto Tuning - Pedagogia por competências. Disponível em: <http://www.dges.mctes.pt/ DGES/pt/Estudantes/Processo+de+Bolonha/Objectivos/Descritores+Dublin/> Acesso em: 26 maio 2010.

Projeto Tuning - Políticas de Educação. Disponível em: <http://ec.europa.eu/education/policies/ educ/Tuning/Tuning_es.html> Acesso em: 23 dez. 2009.

Projeto Tuning - Tipos de competências. Disponível em: <http://www.uva.es/> Acesso em: 21 set. 2009.

Projeto Tuning - objetivos. Disponível em: <http://Tuning.unideusto.org/Tuningal/ index.php?option $=$ content\&task=view\&id=171\&Itemid=199> Acesso em: 23 maio 2008 .

Projeto Tuning - Competências Genéricas da América Latina. Disponível em: <http:// Tuning.unideusto.org/Tuningal $/$ index.php?option=content\&task=view\&id=217\&Itemid=246> Acesso em: 23 maio 2008.

Projeto Tuning Europeu - Países e Universidades participantes. Disponível em: <http:// www.unideusto.org/tuningeu/subject-areas.html> Acesso em: 31 ago. 2011.

Projeto Tuning América Latina — Países e Universidades participantes. Disponível em: <http:// tuning.unideusto.org/tuningal $/$ index.php?option=content\&task=view\&id=40\&Itemid=64> Acesso em: 31 ago. 2011. 
Projeto Tuning — Reflexões e perspectivas do ensino superior na América Latina. Disponível em: <http://www.unideusto.org/tuningeu/images/stories/Publications/Tuning_A_Latina_ Portu_1.pdf> Acesso em: 31 ago. 2011.

\section{Anexo 1 - Universidades participantes do Tuning Europeu, por país}

\section{Alemanha}

Fachhochschule Osnabrück

Zwickau University of Applied Sciences

Universität Göttingen

Aachen University of Applied Sciences

University of Dortmund

Universität Heidelberg

Universität Bochum

Technische Universität Braunschweig

Alice Salomon University of Applied Sciences

Universität Hannover

\section{Áustria}

Universität Innsbruck

Vienna University of Technology

Universität Wien

Paedagogische Akademie des Bundes in Oberoesterreich

Danube University Krems

Universität Graz

TUG Graz University of Technology

Technische Universität Wien

\section{Bélgica}

UFSIA Universiteit Antwerpen

University of Liège

Universiteit Gent

Université Libre de Bruxelles (ULB)

Arteveldehogeschool

\section{Bulgária}

University of Rousse

Plovdiv University

\section{Croácia}

University of Zagreb

\section{Dinamarca}

The Aarhus School of Business

Aarhus Universitet

The Danish University of Education

Universitet Roskilde

Technical University of Denmark

The School of Nursing. University College Jutland

University of Copenhagen

\section{Eslováquia}

University of Economics, Bratislava

Comenius University

\section{Eslovênia}

University of Ljubljana

\section{Espanha}

Universidad de Salamanca

Universidad Complutense de Madrid

Universitat de Barcelona

University of Deusto

Universitat de Valencia

Universidad de Cantabria

Universidad Autónoma de Madrid

Universidad de Zaragoza

Universidad de Granada

\section{Estônia}

University of Tartu

\section{Finlândia}

University of Helsinki

University of Oulu

University of Jyväskylä

University of Turku

University of Tampere

Helsingin Yliopisto 


\section{França}

Ecole Supérieure de Commerce de Lille

CPE Lyon

Université de Marne la Vallée

Université des Sciences et Technologies de Lille

Université Paris X Nanterre

ENS Lettres et Sciences Humaines

Université Pierre Mendès France

Université Paris IX Dauphine

Université de Nice Sophia Antipolis

Université Pierre et Marie Curie, Paris VI

\section{Grécia}

Panepistimion Patron

Athens University of Economics and Business

Aristotle University of Thessaloniki

University of Peleponnese

University of Crete

\section{Holanda}

Tilburg University

University of Amsterdam

Vrije Universiteit Amsterdam

Rijksuniversiteit Groningen

Katholieke Universiteit Nijmegen

Hanzehogeschool Groningen

University of Nijmegen

\section{Hungria}

Eötvos Loránd Tudományegyetem

Eötvos Loránd University

Semmelweis University

\section{Irlanda}

Trinity College Dublin

University College Cork — National University of Ireland

National University of Ireland, Galway

University College Cork
University of Limerick

Waterford Institute of Technology

Dublin City University

\section{Islândia}

University of Iceland

Itália

Università degli Studi di Pavia

Università di Bologna

Università degli Studi Roma Tre

Università degli Studi di Genova

Università degli Studi di Roma "La Sapienza"

Università degli Studi di Padova

Unversità degli Studi di Pisa

ECTS Counsellor

Università di Padova

University of Trieste

Kosovo

University of Prishtina

\section{Latvia}

University of Latvia

\section{Lituânia}

Vilnius University

\section{Malta}

University of Malta

\section{Macedônia}

Sts. Cyril and Methodius University

\section{Noruega}

Norwegian School of Economics and Business Administration

University of Bergen

University of Oslo

University of Tromso

Agder University College

Polônia

Jagiellonian University

University of Nicholas Copernicus

Medical University Lublin 


\section{Portugal}

Universidade Técnica de Lisboa - Instituto Superior de Economia e Gestão

Universidade de Évora

Universidade Aberta

Universidade de Coimbra

Universidade do Porto

Universidade de Aveiro

\section{Reino Unido}

Loughborough University

University of Strathclyde

University of Edinburgh

Imperial College of Science, Technology and Medicine

University of Bristol

London Metropolitan University

University of Wales Swansea

University of Westminster

University of Southampton

Imperial College London

University of Bath

\section{República Tcheca}

Charles University of Prague
Mendel University of Agriculture and Forestry Brno

\section{Romênia}

Alexandru Ioan Cuza University

University of Bucharest

\section{Sérvia e Montenegro}

University of Novi Sad

\section{Suécia}

University of Umea

Lund University

Göterborg University

University of Uppsala

Chalmers University of Technology

\section{Suíça}

University of Fribourg

University of Lausanne

\section{Ucrânia}

Odessa State Economics University

Bogomolets Medical University

National Technical University Kharkiv Polytechnic Institute

\section{Anexo 2 - Universidades participantes do Tuning América Latina, por país}

\section{Argentina}

Universidad de Belgrano

Universidad Nacional de Cuyo

Universidad Nacional de La Plata

Universidad de San Andrés

Universidad Nacional del Centro de la Provincia de Buenos Aires

Universidad de Buenos Aires

Universidad Nacional de Córdoba

Bolívia

Universidad Privada Santa Cruz de la Sierra
Universidad Núr

Universidad Mayor de San Simón

\section{Brasil}

Universidade Estadual de Londrina - UEL

Universidade Federal de Pernambuco - UFPE

Universidade Federal do Rio de Janeiro

Universidade de Brasília

Universidade Presbiteriana Mackenzie de São Paulo

Universidade Estadual de Campinas UNICAMP 
Universidade Federal de Minas Gerais UFMG

Universidade do Estado do Rio de Janeiro

Universidade Federal do Ceará

Universidade Federal do Rio Grande do Sul

Universidade Federal de Ouro Preto

Universidade Federal do Pará

Pontifícia Universidade Católica do Rio de Janeiro - PUC/RJ

Universidade Federal de Santa Catarina

Universidade Federal de Uberlândia

Universidade de Caxias do Sul - UCS

Universidade Federal da Bahia - UFBA

Universidade Federal de São Paulo

Universidade de São Paulo

\section{Chile}

Universidad de Talca

Universdiad Católica de Valparaíso

Universidad Católica de Chile

Universidad Metropolitana de Ciencias de la Educación

Universidad de Chile

\section{Colômbia}

EAFIT

Universidad del Norte

Pontificia Universidad Javeriana

Universidad Nacional

Universidad de Antioquia

\section{Costa Rica}

Universidad de Costa Rica

Universidad Nacional

\section{Cuba}

Centros Rectores — Universidad de La Habana

\section{Equador}

Universidad Tecnológica Equinoccial

Universidad de Guayaquil

Pontificia Universidad Católica del Ecuador

Universidad de las Américas

\section{El Salvador}

Universidad Centroamericana "José Simeón Cañas"

Universidad de El Salvador

\section{Guatemala}

Universidad de San Carlos de Guatemala

Universidad Rafael Landivar

\section{Honduras}

Universidad Nacional Autónoma de Honduras

Universidad Pedagógica Nacional

\section{México}

Instituto Tecnológico y de Estudios Superiores de Monterrey

Universidad de Guanajuato

Universidad Autónoma del Estado de Hidalgo

Benemérita Universidad Autónoma de Puebla

Universidad Autónoma de Yucatán

Universidad Autónoma Metropolitana

Universidad de Colima

\section{Nicarágua}

Universidad Politécnica de Nicaragua (UPOLI)

Universidad Nacional Autónoma de Nicaragua

- Managua

\section{Panamá}

Universidad Santa María la Antigua

Universidad de Panamá

\section{Paraguai}

Universidad Nacional de Asunción

\section{Peru}

Universidad del Pacífico

Universidad Peruana Unión

Universidad Nacional Mayor de San Marcos

(UNMSM)

Universidad Nacional de Ingenierías

República Dominicana

Universidad APEC 
Universidad Iberoamericana UNIBE

Instituto Tecnológico de Santo Domingo

Universidad Autónoma de Santo Domingo

\section{Uruguai}

Universidad de La República

\section{Venezuela}

Universidad Católica Andrés Bello

Universidad Simón Rodríguez

Universidad Central de Venezuela

Universidad de Carabobo

Fonte: $<$ http: $/ /$ tuning.unideusto.org $/$ tuningal $/$ index.php?option $=$ content $\&$ task $=$ view $\&$ id $=40 \&$ Itemid $=64>$ Acesso em: 31 ago. 2011. 